\title{
COMPARAÇÃO DA PRODUTIVIDADE DE SOJA OBSERVADA E SIMULADA PELO MODELO SOYSIM PARA SEIS MUNICÍPIOS DO RIO GRANDE DO SUL
}

\author{
Jossana Ceolin Cera ${ }^{1}$, Ânthony Paz Cardoso², Alencar Júnior Zanon ${ }^{3}$, Nereu Augusto \\ Streck $^{4}$, Gizelli Moiano de Paula ${ }^{5}$, José Eduardo Minussi Wink ${ }^{6}$, Gean Leonardo Richter ${ }^{7}$, \\ Thiago Schmitz Marques da Rocha ${ }^{8}$ \\ ${ }^{1}$ Universidade Federal de Santa Maria \\ jossana.cera@gmail.com ${ }^{1}$
}

RESUMO: A produtividade da cultura da soja foi simulada por um modelo ecofisiológico e comparada com dados de produtividade observada de seis municípios do Rio Grande do Sul - RS. As simulações foram realizadas através do modelo SoySim, com quatro datas de semeadura, três grupos de maturação e três níveis tecnológicos distintos.

\begin{abstract}
The yield of soybean was simulated by an ecophysiological model and compared with data yield observed from six cities of Rio Grande do Sul. The simulations were performed using the model SoySim, with four dates seeding, three maturation groups and three different technological levels.
\end{abstract}

\section{INTRODUÇÃO}

A soja (Glycine $\max (\mathrm{L}$.$) Merrill) é uma das principais culturas agrícolas do Brasil e a$ principal fonte de óleo vegetal do mundo. No RS, na safra 2012/2013 foram cultivados em torno de 4,6 milhões de hectares e colhidos em torno de 12,2 milhões de toneladas de soja (IBGE, 2013), sendo assim a cultura agrícola mais importante desse Estado.

Modelos de simulação do crescimento, desenvolvimento e produtividade têm sido propostos para inúmeras culturas, incluindo a soja (SETIYONO et al., 2007, SETIYONO et al., 2008). O SoySim é um modelo recente e moderno de simulação de crescimento, desenvolvimento e produtividade de grãos da cultura da soja (SETIYONO et al., 2010) desenvolvido e testado 
no EUA. Atualmente, o grupo de Agrometeorologia da UFSM está avaliando o SoySim nas condições de cultivo do RS. O objetivo do trabalho foi verificar qual nível de manejo ou nível tecnológico inicial da lavoura, no SoySim, em que a produtividade mais se aproxima da produtividade de lavouras comerciais de seis municípios do RS.

\section{MATERIAL E MÉTODOS}

Este estudo foi realizado para seis municípios do RS, durante o ano agrícola 2012/2013, Santa Maria, Passo Fundo, Bagé, Uruguaiana, Camaquã, e Santa Rosa. Estes municípios foram escolhidos em função da variação do rendimento da cultura da soja e, também, por estarem espacialmente bem distribuídos no Estado. O ano 2012/2013 foi selecionado pela sua elevada produtividade, principalmente porque não houve deficiência hídrica no Estado. A produtividade observada nos municípios foi a do IBGE (IBGE, 2013) e a produtividade simulada pelo SoySim foi considerada a média de quatro datas de semeadura, dentro do período recomendado pelo zoneamento agroclimático da cultura da soja no RS (15/10, 05/11, 25/11 e 15/12) e três grupos de maturação (GM 5, 6, 7), por estes serem os mais cultivados no RS.

Para cada uma destas datas e GM, o SoySim foi rodado em três níveis tecnológicos ou de manejo iniciais de lavoura (ótimo, médio e baixo). Os dados meteorológicos que são inputs do SoySim foram os das estações meteorológicas pertencentes ao INMET (Instituto Nacional de Meteorologia) nas cidades. Também foram informados dados como hábito de crescimento (indeterminado) e densidade de plantas (300.000 pl/ha).

\section{RESULTADOS E DISCUSSÃO}

Para os níveis de manejo Ótimo e Médio, as produtividades ficaram em torno de 3,5 t/ha e 3,4 t/ha, respectivamente, para os seis municípios. Já o nível de manejo Baixo a produtividade variou de 2 a 2,8 t/ha. Os dados fornecidos pelo IBGE representam a produtividade média de cada município, ou seja, a produtividade em cada município depende do tipo de solo, condições meteorológicas e das práticas de manejo realizadas pelos agricultores, e variaram de 1,3 a 3,0 kg/ha.

Comparando os valores de rendimento do IBGE com os valores simulados, os municípios de Bagé, Camaquã, Santa Rosa, Uruguaiana e Santa Maria tiveram produtividades mais 
próximas do nível de manejo Baixo. Apenas Passo Fundo (Figura 2c) teve produtividade próxima ao nível de produtividade Médio. Passo Fundo é um dos municípios do Rio Grande do Sul com o maior potencial produtivo e com o maior nível tecnológico na produção de soja. Santa Maria (Figura 2f) teve valores observados de produtividade maiores que Santa Rosa (Figura 2b). Santa Rosa tem melhores condições de solo e clima para soja do que Santa Maria. Analisando os dados meteorológicos, houve um período com déficit hídrico nos primeiros 40 dias de 2013, que coincidiu com a época de floração e enchimento de grãos da cultura, que pode explicar a menor produtividade em Santa Rosa neste ano agrícola.
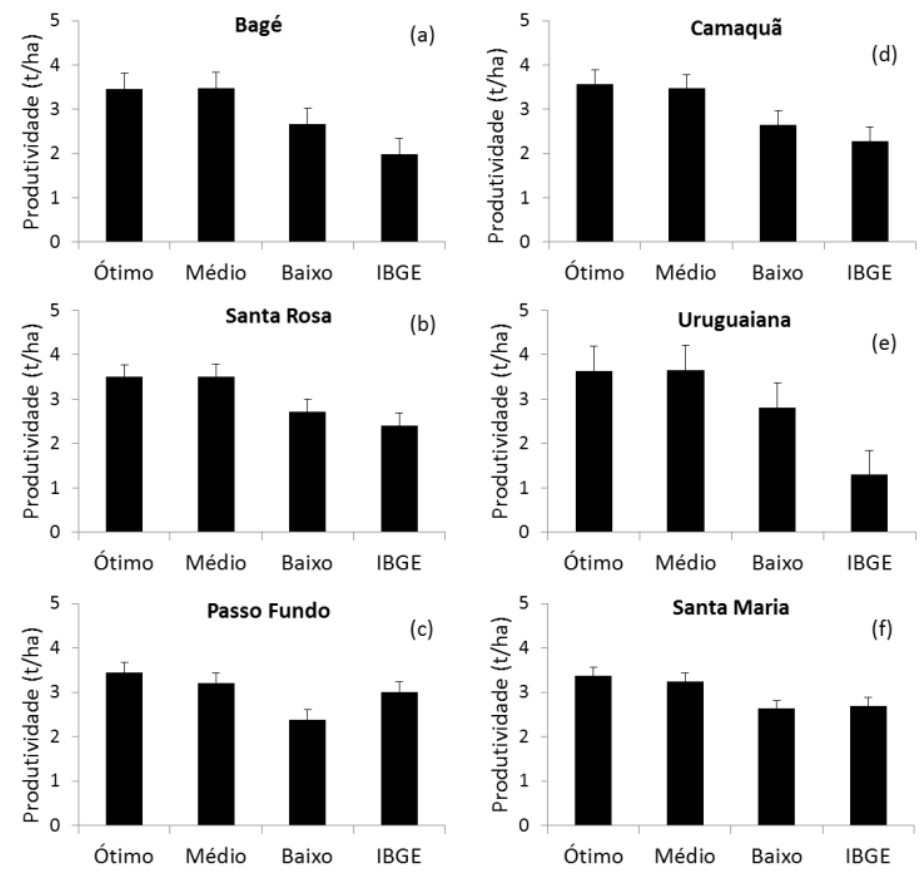

Figura 2. Produtividade de soja simulada pelo modelo SoySim com nível de manejo Ótimo, Médio e Baixo e observada (dados do IBGE), para seis municípios do Rio Grande do Sul (a) Bagé, (b) Santa Rosa, (c) Passo Fundo, (d) Camaquã, (e) Uruguaiana e (f) Santa Maria, no ano agrícola 2012/2013.

\section{CONCLUSÃO}

O potencial de produtividade de soja nos seis municípios é em torno de $3,5 \mathrm{t} / \mathrm{ha}$, porém a produtividade observada em cinco municípios foi de 1 a 2,5t/ha (próxima do nível Baixo de tecnologia inicial simulado pelo SoySim) e em um município (Passo Fundo) foi de 3t/ha, correspondendo ao nível tecnológico inicial Médio. 


\section{AGRADECIMENTOS}

Ao CNPq pelo apoio financeiro e à Universidade Federal de Santa Maria pelo suporte físico.

\section{REFERÊNCIAS}

IBGE. Instituto Brasileiro de Geografia e Estatística. Disponível em <http://www.ibge.gov.br/home>. Acesso em: 18 de Junho de 2013.

SETIYONO, T.D.; WEISS, A.; SPECHT, J.; BASTIDAS, A.M.; CASSMAN K.G.; DOBERMANN, A. Understanding and modeling the effect of temperature and daylength on soybean phenology under high-yield conditions. Field Crops Research, v.100, p.257-271, 2007.

SETIYONO, T.D.; WEISS, A.; SPECHT, J. E.; CASSMAN K.G.; DOBERMANN, A. Leaf area index simulation in soybean grown under near-optimal conditions. Field Crops Research, v.108, p. 82-92, 2008.

SETIYONO, T.D.; CASSMAN K.G.; SPECHT, J. E.; DOBERMANN, A.; WEISS, A.; YANG, H.; CONLEY, S.P.; ROBINSON, A.P.; PEDERSEN, P.; DE BRUIN, J.L. Simulation of soybean growth and yield in near-optimal growth conditions. Field Crops Research, v.119, p.161-174, 2010. 